\title{
Neuromuscular and vascular hamartoma of small bowel
}

\section{S S E FERNANDO* and V J MCGOVERN}

From the Departments of Pathology, Royal Prince Alfred Hospital, and The University of Sydney, Sydney, NSW, Australia

SUMmARY Two examples of a hitherto undescribed hamartomatous condition of the small intestine are presented. They consist of fascicles of smooth muscle derived from the muscularis mucosae, bundles of unmyelinated nerve fibres with scattered ganglion cells, and haemangiomatous vessels, occurring focally within a segment of the intestine, and causing stenosis.

\section{Case 1}

A 30 year old Indonesian woman was investigated for chronic blood loss from the gastrointestinal tract. She was known to have been anaemic since the age of four years. Serial contrast radiographic studies of the small bowel showed multiple strictures in the lower ileum for which she underwent laparotomy. One hundred and eight centimetres of ileum were removed and an end-to-end enteroenterostomy was

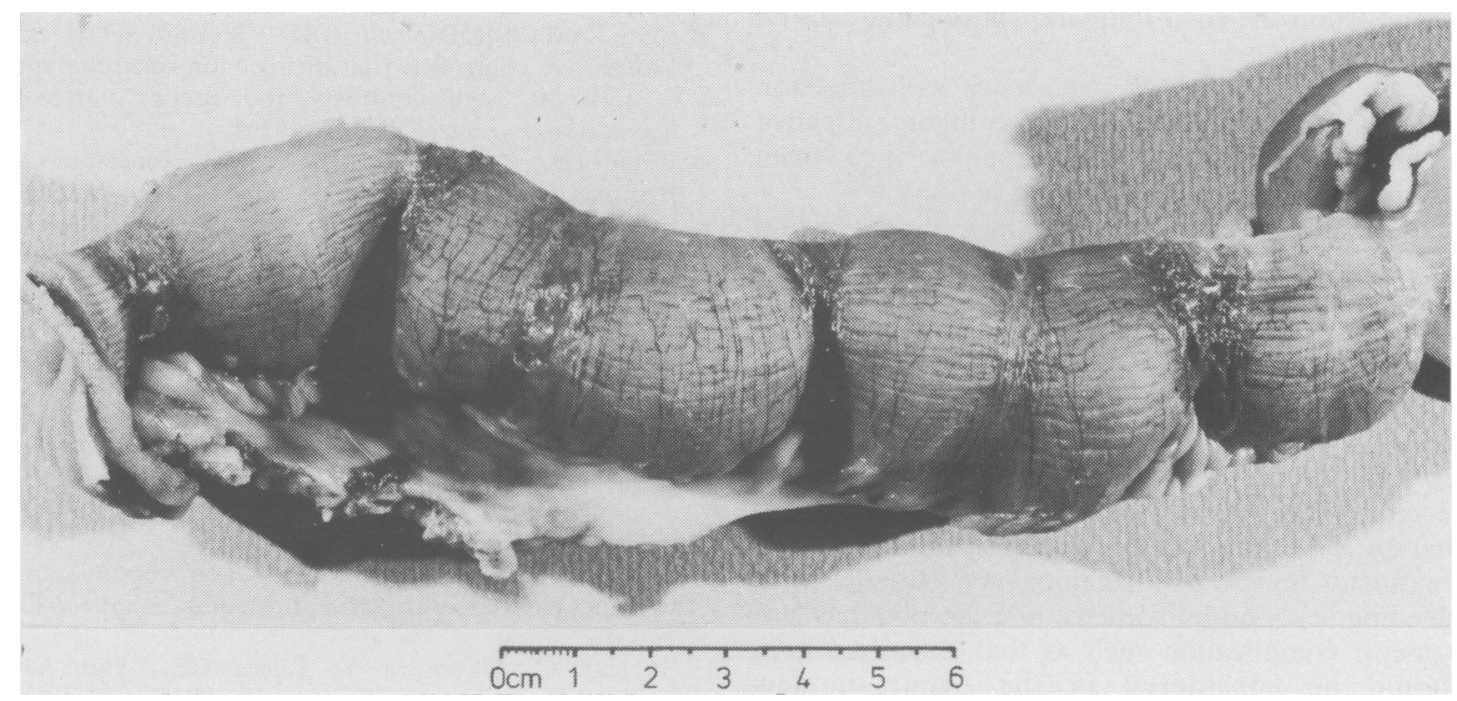

Fig. 1 Case 1. Annular constriction in ileum spaced at 3-4 cm intervals.

* Address for correspondence: Dr S S E Fernando. Histopathology Department, The Liverpool Hospital, Box 103 PO, Liverpool, NSW 2170. Australia.

Received for publication 15 February 1982 performed. There were annular constrictions in the resected ileum spaced at intervals of $3-4 \mathrm{~cm}$ along most of the specimen (Fig. 1). Between the constrictions, the bowel wall was thicker and more rigid 


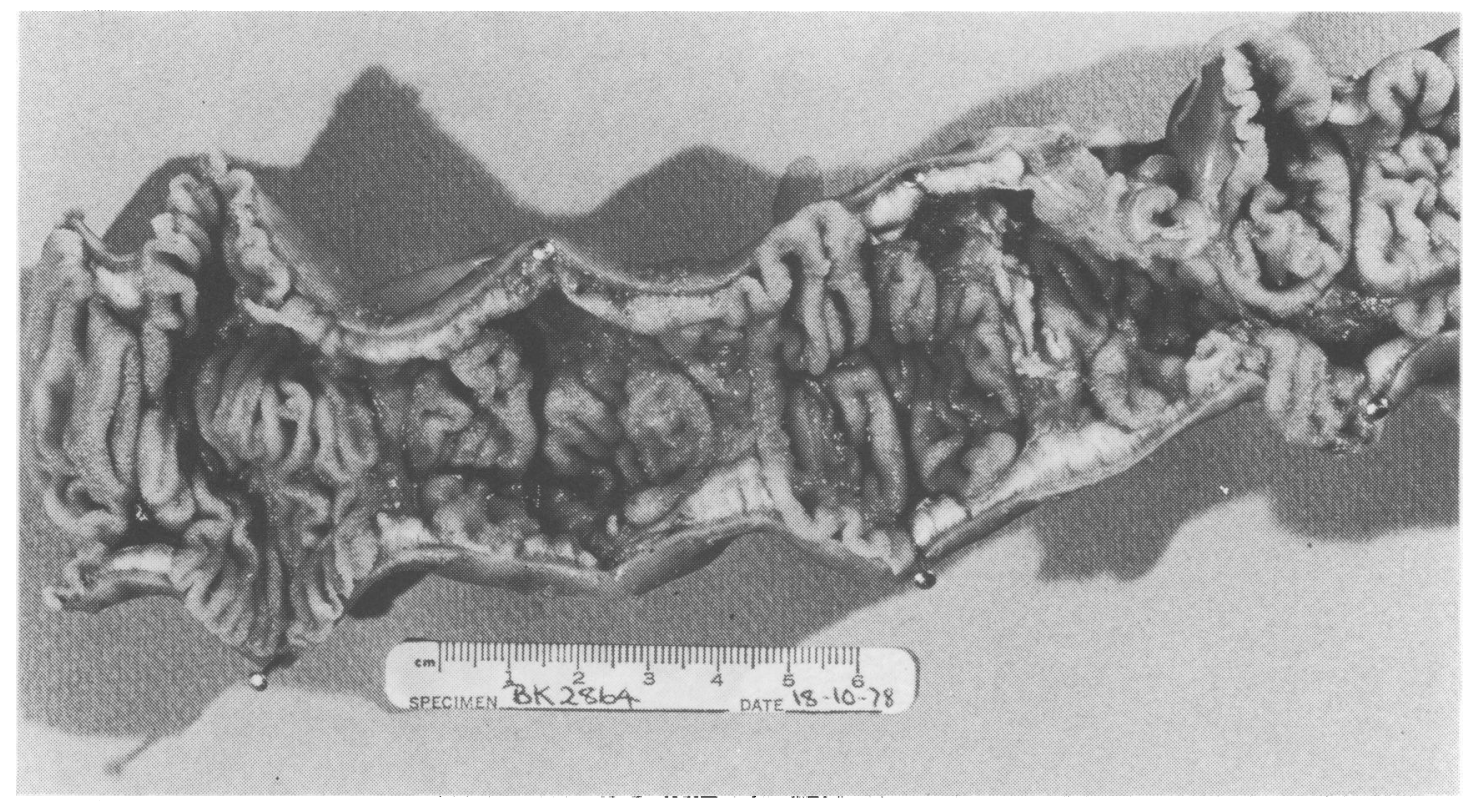

Fig. 2 Case 1. Submucosal thickenings with ulceration, corresponding to constrictions.

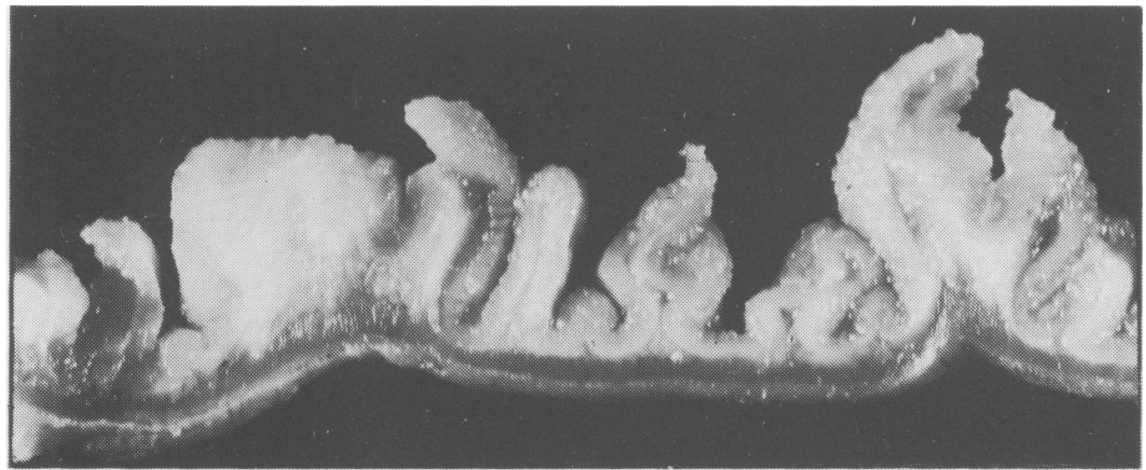

Fig. 3 Case 1. Longitudinal section of specimum showing focal thickenings of submucosa.

than normal. On the mucosal surface corresponding to the constrictions there were ulcers, most of which were annular but some of which were longitudinal, corresponding to the attachment of the mesentery (Fig. 2). There were areas of dense white thickening of the submucosa and hypertrophy of the muscularis propria at the affected sites (Figs. 2 and 3). Examination by light microscopy showed aberrant fascicles of muscle from the muscularis mucosae entering the submucosa together with bundles of non-myelinated nerve fibres and scattered ganglion cells together with blood vessels (Fig. 4). The lymph nodes were normal.

ELECTRON MICROSCOPY (Dr E Wills)

The submucosa showed considerable numbers of smooth muscle cells in bundles of closely apposed cells, and also more loosely scattered between the other connective tissue elements. There were many small unmyelinated nerve fibres with prominent Schwann cells. Although nerves and muscle fibres were often in close proximity, no neuromuscular junctions were found. Small muscular vessels were also rather prominent. 

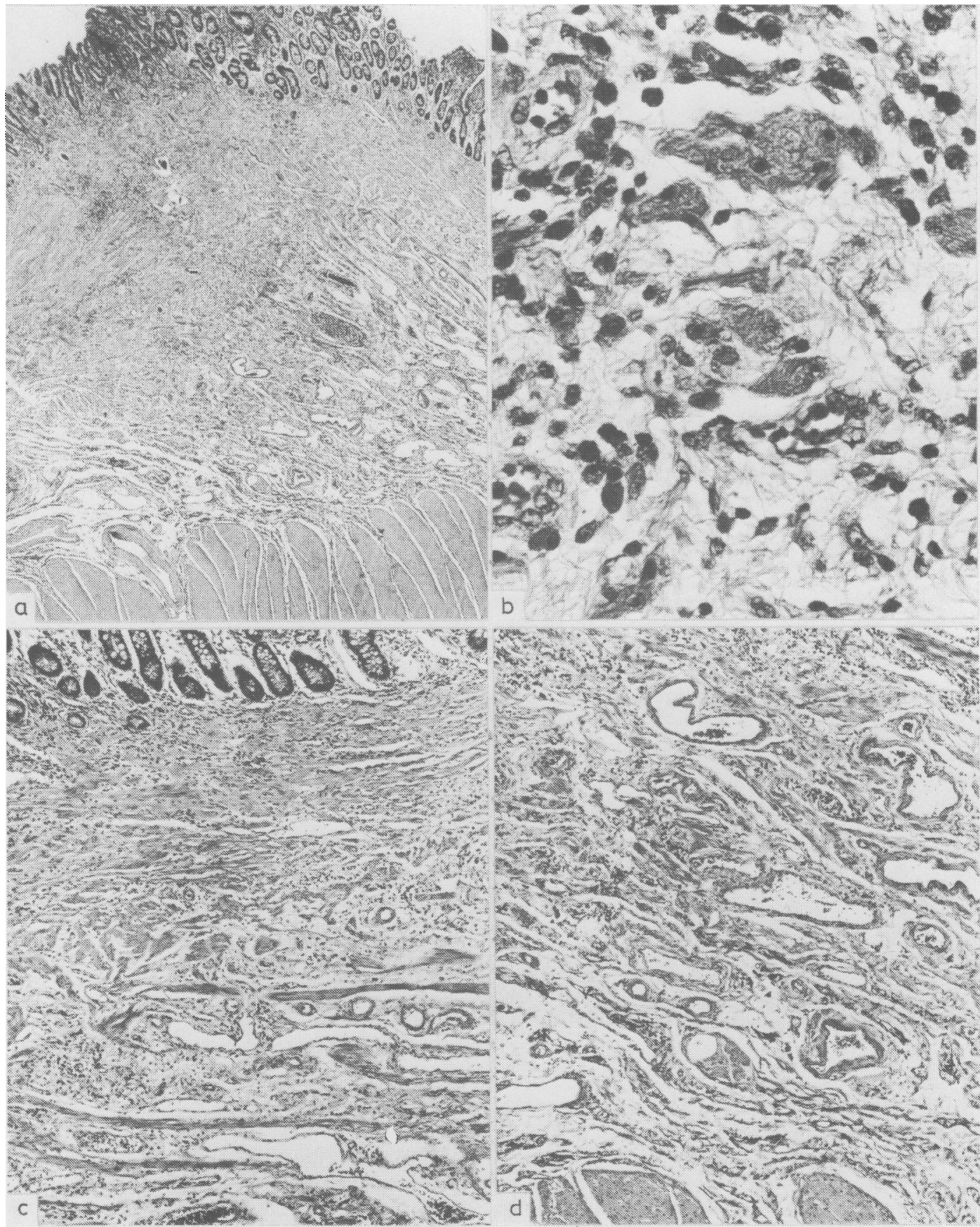

Fig. 4 Case 1. (a) A panoramic view showing thickening of the submucosa due to proliferation of muscle fascicles, nerve, blood vessels, and collagen. $H$ and $E \times 16$. (b) Scattered ganglion cells in a meshwork of unmyelinated fibres. There is a light inflammatory infiltrate consisting of lymphocytes and plasma cells. $H$ and $E \times 300$. (c) Upper half of submucosa showing horizontal strands of smooth muscle and numerous blood vessels. $H$ and $E \times 120$. (d) Lower half of submucosa showing bundles of nerve fibres and smooth muscle. $A$ vessel in the lower half of the photomicrograph has asymmetrical thickening of the media. $H$ and $E \times 120$. 


\section{Case 2}

This 36 year old white Australian woman was admitted with a history of persistent vomiting, abdominal pain, and constipation present for two weeks. Apart from a cholecystectomy in 1978 and a tubal ligation with appendicectomy in 1972 she had no other illness. She was pale and afebrile with no evidence of cardiovascular, respiratory, or thyroid disease. Her abdomen was soft, with tenderness in the epigastrium and right iliac fossa. Rectal examination revealed no abnormality.

The blood count was normal $(\mathrm{Hb} 13.3 \mathrm{~g} / \mathrm{dl})$. She was treated for small bowel obstruction possibly related to adhesions, with nasogastric suction and intravenous fluids. She made good progress. However when nasogastric suction was stopped and oral fluids started again, she once more became distended and had abdominal pain. Radiographic examination showed some dilated loops of small bowel.

In August 1979, 11 days after admission, a laparotomy was performed, and a $30 \mathrm{~cm}$ segment of jejunum was resected.

Ten centimetres from one end there was a narrowed segment $5 \mathrm{~cm}$ long. Proximal to the obstruction the bowel was dilated. At the proximal end of the narrowed segment there was an ulcer 1.3 $\mathrm{cm}$ in the transverse direction and $0.6 \mathrm{~cm}$ in length on the mesenteric border (Fig. 5).

The appearances, both microscopically and ultrastructurally of the narrowed segment were similar to those in case 1 .

\section{Discussion}

As the condition we have described consists of an aberrant, non-neoplastic arrangement of tissue normally occurring in the small intestine, we have designated it a neuromuscular and vascular hamartoma. Lesions arising form nerve elements indigenous to the gut are extremely rare and it is difficult to separate true tumours from harmartomatous lesions. Morson and Dawson ${ }^{1}$ group together a wide variety of lesions such as ganglioneuromas, paragangliomas, glomus tumours, and other harmatomatous lesions, in the category of neurinomatous hyperplasia.

Cooney and Sweeney ${ }^{2}$ describe a paraganglioneuroma of the duodenum where on light microscopy the neural component of a hybrid neural and endocrine tumour was characterised by ganglion cells and endocrine type cells.

No such endocrine type cells were present in our two cases. Further, electron microscopy did not show any 'pale' and 'dark' cells corresponding to the epitheloid cells containing neurosecretory granules and spindle cells containing neurofilaments.

Multiple concentric strictures found in adult life are sometimes ischaemic in origin and can be accompanied by hyperplasia of muscularis mucosae and incorporation of ganglion cells.

Healed ischaemic lesions, however, give rise to very dense fibrosis with foci of smooth muscle fibre 'drop out' even in areas adjacent to strictures and ulcerations; which was not found in our case. ${ }^{3}$ We feel that in our two cases the admixture of nonmyelinated nerve fibres, scattered ganglion cells, smooth muscle, connective and vascular tissue constitutes a specific condition.

Neither of our patients had any manifestation of multisystemic disease such as neurofibromatosis or Sipple's syndrome, in which neural tissues may participate. In each case the condition was an independent entity.

We have not found any similar case in the medical literature.

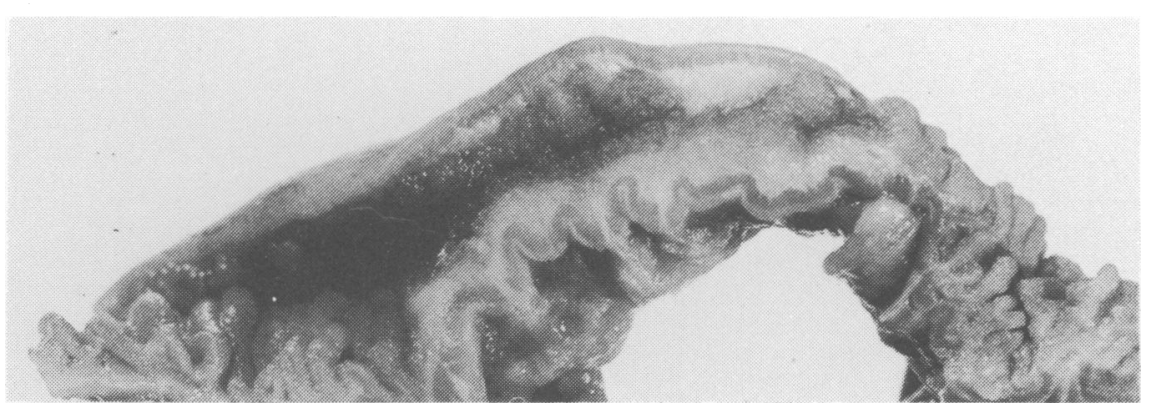

Fig. 5 Case 2. Portion of the resected specimen showing the segment with thickening of the submucosa. 


\section{References}

1 Morson BC, Dawson IMP. Gastro-intestinal pathology. Oxford: Blackwell 1979: 423-32.
2 Cooney T, Sweeney EC. Paraganglioneuroma of the duodenum: an evolutionary hybrid? J Clin Pathol 1978; 31: 233-44.

3 McGovern VJ, Tiller DJ. Shock: a clinicopathologic correlation. USA Inc: Mason 1980. 